\title{
Deterministic placement of ultra-bright near-infrared color centers in arrays of silicon carbide micropillars
}

\author{
Stefania Castelletto ${ }^{* 1}$, Abdul Salam Al Atem², Faraz Ahmed Inam ${ }^{3}$, \\ Hans Jürgen von Bardeleben ${ }^{4}$, Sophie Hameau ${ }^{4}$, Ahmed Fahad Almutairi ${ }^{1}$, \\ Gérard Guillot ${ }^{2}$, Shin-ichiro Sato ${ }^{5}$, Alberto Boretti ${ }^{6,7}$ and Jean Marie Bluet ${ }^{2}$
}

\author{
Full Research Paper \\ Address: \\ ${ }^{1}$ School of Engineering, RMIT University, Melbourne, Victoria 3001, \\ Australia, ${ }^{2}$ Univ Lyon, INSA Lyon, CNRS, INL, UMR5270, F-69621 \\ Villeurbanne, France, ${ }^{3}$ Dept. of Physics, Aligarh Muslim University, \\ Aligarh, U.P. 202002, India, ${ }^{4}$ Sorbonne Université, Campus Pierre et \\ Marie Curie, Institut des Nanosciences de Paris, 4, place Jussieu, \\ 75005 Paris, France, ${ }^{5}$ National Institutes for Quantum and \\ Radiological Science and Technology, Takasaki, Gunma, 370-1292, \\ Japan, ${ }^{6}$ Department of Mechanical Engineering, College of \\ Engineering, Prince Mohammad Bin Fahd University, Al Khobar, \\ 34754, Saudi Arabia and ${ }^{7}$ Faculty of Applied Sciences, Ton Duc \\ Thang University, Ho Chi Minh City, 758307, Vietnam \\ Email: \\ Stefania Castelletto* - stefania.castelletto@rmit.edu.au \\ * Corresponding author \\ Keywords: \\ color centers; micropillars; proton irradiation; quantum sensing; silicon \\ carbide; vacancy \begin{abstract}
doi:10.3762/bjnano.10.229
Received: 21 September 2019

Accepted: 20 November 2019

Published: 05 December 2019

Associate Editor: E. Meyer
\end{abstract} \\ Beilstein J. Nanotechnol. 2019, 10, 2383-2395. \\ (C) 2019 Castelletto et al.; licensee Beilstein-Institut. \\ License and terms: see end of document.
}

\footnotetext{
Abstract

We report the enhancement of the optical emission between 850 and $1400 \mathrm{~nm}$ of an ensemble of silicon mono-vacancies $\left(\mathrm{V}_{\mathrm{Si}}\right)$, silicon and carbon divacancies $\left(\mathrm{V}_{\mathrm{C}} \mathrm{V}_{\mathrm{Si}}\right)$, and nitrogen vacancies $\left(\mathrm{N}_{\mathrm{C}} \mathrm{V}_{\mathrm{Si}}\right)$ in an n-type $4 \mathrm{H}$-SiC array of micropillars. The micropillars have a length of ca. $4.5 \mu \mathrm{m}$ and a diameter of ca. $740 \mathrm{~nm}$, and were implanted with $\mathrm{H}^{+}$ions to produce an ensemble of color centers at a depth of approximately $2 \mu \mathrm{m}$. The samples were in part annealed at different temperatures (750 and $900{ }^{\circ} \mathrm{C}$ ) to selectively produce distinct color centers. For all these color centers we saw an enhancement of the photostable fluorescence emission of at least a factor of 6 using micro-photoluminescence systems. Using custom confocal microscopy setups, we characterized the emission of $\mathrm{V}_{\mathrm{Si}}$ measuring an enhancement by up to a factor of 20 , and of $\mathrm{N}_{\mathrm{C}} \mathrm{V}_{\mathrm{Si}}$ with an enhancement up to a factor of 7 . The experimental results are supported by finite element method simulations. Our study provides the pathway for device design and fabrication with an integrated ultra-bright ensemble of $\mathrm{V}_{\mathrm{Si}}$ and $\mathrm{N}_{\mathrm{C}} \mathrm{V}_{\mathrm{Si}}$ for in vivo imaging and sensing in the infrared.
} 


\section{Introduction}

Silicon carbide $(\mathrm{SiC})$ is an established material for many electronic devices and has also been considered for photonics applications recently. After the improvement of the purity of the material and the isolation of point defects (primarily vacancies), $\mathrm{SiC}$ has been considered to host physical systems for quantum devices such as single-photon sources and spin-photon interfaces for quantum interconnects [1-3]. Points defects or color centers in $\mathrm{SiC}$ are considered as alternative candidates for quantum applications such as solid-state quantum bits [4,5], spin-photon interfaces [6], single-photon sources (SPSs) [7-10], nanoscale magnetic or electric fields sensors, and pressure or temperature sensors [3,11-13]. Electrically driven SPSs in SiC have been realized [14-16], and the coherent control of electron spin can be achieved up to $500 \mathrm{~K}$ [17]. SiC offers an alternative platform for the integration of these quantum systems in largescale complementary metal-oxide semiconductor (CMOS)compatible wafers. Also, $\mathrm{SiC}$ is suitable for nanofabrication $[18,19]$, and can be controlled through its electronic and piezoelectric properties. Further, it has great potentials for integrated quantum photonics as it has been identified as next-generation photonics material, owing to its second-order nonlinearity, low two-photon absorption, and wide optical transparency. However, there are still many challenges regarding both material fabrication and generation of color centers for integrated photonics applications.

Most of SiC point defects were found more than one decade ago with methods based on measuring ensemble photoluminescence (PL) [20], i.e., the light emission after the absorption of photons, and electron paramagnetic resonance (EPR) [21], which reveals unpaired electrons. Current studies aim to determine more accurately the quantum properties of these defects by using more recent methods of single-photon detection and single-color center isolation, and quantum coherent spin control. The parameters used to describe the quantum properties of color centers include zero-phonon line (ZPL) [22], Debye-Waller factor (DWF) [23,24], zero-field-splitting (ZFS) [25] and optically detected magnetic resonance (ODMR) [26]. The ZPL and the phonon sideband together determine the line shape of individual light-absorbing and emitting molecules [22]. The DWF describes the thermal motion attenuation of X-ray or coherent neutron scattering $[23,24]$. The DWF can be estimated as the ratio of the ZPL PL emission, compared to the total PL emission, which is the combination of the ZPL PL emission and the phonon-broadened PL. The ZFS refers to the lifting of degeneracy in the absence of a magnetic field. Unpaired electrons interact to give two or more energy states [25]. ODMR is a technique to optically pump the electron spin state of a crystal defect for spin initialization and readout [26].
There are over 200 polymorphs of $\mathrm{SiC}$, and the most relevant are cubic $\mathrm{SiC}(3 \mathrm{C})$ and hexagonal $(4 \mathrm{H}$ and $6 \mathrm{H})$, which have different materials properties. The most extensively studied point defects for the quantum technologies described above, specifically for the spin-photon interface, appear in hexagonal $4 \mathrm{H}-\mathrm{SiC}$, namely the silicon monovacancy and the silicon and carbon divacancy $\left(\mathrm{V}_{\mathrm{Si}}, \mathrm{V}_{\mathrm{Si}} \mathrm{V}_{\mathrm{C}}\right)$ [27]. The $\mathrm{V}_{\mathrm{Si}}{ }^{(-)}$[28] has two ZPLs, V1/V1' at 862 and $859 \mathrm{~nm}$, and V2 at $917.5 \mathrm{~nm}$ in the $4 \mathrm{H}$ polymorph. It has been established to have a spin number of $3 / 2$ and a negative charge state $[29,30]$. These lines correspond to the two inequivalent cubic (V2) and hexagonal (V1/V1', with $\mathrm{V}^{\prime}$ ' as a second excited state) sites in $4 \mathrm{H}-\mathrm{SiC}$. The intensity of the largest PL from a single defect at saturation is $10 \mathrm{kcts} / \mathrm{s}$ [8] without a solid immersion lens using an a-Si detector with 20-30\% quantum efficiency and $40 \mathrm{kcts} / \mathrm{s}$ with a solid immersion lens [4]. The DWF is $40 \%$, the ZFS is $70 \mathrm{MHz}$ for V2 and $4 \mathrm{MHz}$ for $\mathrm{V} 1$ at the ground state [31]. The maximum optically

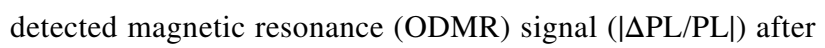
off-resonant optical excitation is 0.04. After resonant optical excitation it is close to $100 \%$ [32]. By using the V1 line of the $\mathrm{V}_{\mathrm{Si}}$, it has been demonstrated that its optical resonances are stable with near-Fourier-transform-limited linewidths, allowing for the exploitation of the spin selectivity of the optical transitions for spin-photon entanglement [33]. In addition to millisecond-long spin coherence times originating from the high-purity crystal, high-fidelity optical initialization and coherent spin control permitted to achieve coherent coupling to single nuclear spins with ca. $1 \mathrm{kHz}$ resolution [27].

The divacancy in $4 \mathrm{H}-\mathrm{SiC}$ is a neutral charge state defect with spin $S=1$ with 4 ZPLs PL1-PL4, in the range of $1078-1132 \mathrm{~nm}$ [34]. The largest PL intensity is $27 \mathrm{kcps}$ [5] at low temperature using a superconducting nanowire detector with $80 \%$ quantum efficiency, and the DWF is $5 \%$. The ZFS is $1.2-1.4 \mathrm{GHz}$ in the ground state and $0.75-0.95 \mathrm{GHz}$ in excited states. Both $\mathrm{V}_{\mathrm{Si}}$ and $\mathrm{V}_{\mathrm{Si}} \mathrm{V}_{\mathrm{C}}$ have been proved to be useful for a high-fidelity spin-photon interface [6,27]. PL spectroscopy and EPR measurements combined with ab initio simulations of the nitrogen vacancy, $\mathrm{N}_{\mathrm{C}} \mathrm{V}_{\mathrm{Si}^{(-)}}(\mathrm{NV})$, defect in $\mathrm{SiC}$ have been recently performed in [35-38], resulting in ZPLs at 1242, 1241, 1223 and $1180 \mathrm{~nm}$ [38]. This emission is very promising as it is further into the infrared compared to the divacancies. The association of ZPL lines with NV centers was eventually demonstrated in [39]. The EPR spin number is 1 and the ZFS is $1.3 \mathrm{GHz}$. The $\mathrm{NV}$ in $\mathrm{SiC}$ has also been deliberately created by using ion irradiation in n-type and intrinsic $4 \mathrm{H}-\mathrm{SiC}$, showing it can be successfully fabricated [40].

As most of the emitters with spin properties in $\mathrm{SiC}$ are in the near-infrared, there is a need to improve the spontaneous emis- 
sion rate for room-temperature applications such as magnetic sensing and SPSs. For all the above applications, the fluorescence emission enhancement of the color centers is a crucial issue for room-temperature applications, specifically for the $\mathrm{V}_{\mathrm{Si}}$ and the nitrogen vacancy $\left(\mathrm{N}_{\mathrm{C}} \mathrm{V}_{\mathrm{Si}}\right)$ [36].

Micropillars in other materials have been successfully used as photonics structures designed to improve the photoluminescence performance of quantum dots for strong coupling of the emission with the photonics cavity, high photon-extraction efficiency and SPS on-demand generation with near-unity indistinguishability [41-43]. Silicon carbide micropillars have been used in unrelated mechanical property studies in the past $[44,45]$. Towards the abovementioned goals, a scalable approach for the design and fabrication of photonics wafers to control the local density of states of the emitters is needed. So far, other photonics structures in $\mathrm{SiC}$ have been shown, such as photonic crystal cavities in cubic $\mathrm{SiC}$ for enhancing the emission of the divacancy $\mathrm{V}_{\mathrm{Si}} \mathrm{V}_{\mathrm{C}}$ and of $\mathrm{V}_{\mathrm{Si}}[18,46,47]$, microdisks for enhancing visible interface defects [48,49], nanopillars in $4 \mathrm{H}-\mathrm{SiC}$ formed by reactive ion etching (RIE) for the improvement of the $\mathrm{V}_{\mathrm{Si}}$ emission collection efficiency [50], and the use of a solid immersion lens (SIL) for an enhancement factor of three of single $V_{S i}$ [4]. Recent results of the successful enhancement of $\mathrm{V}_{\mathrm{Si}}$ in $4 \mathrm{H}-\mathrm{SiC}$ based on nanopillars [50] provided an equivalent enhancement (factor of three) of SIL but with a smaller footprint and better scalability.

The sensitivity of quantum magnetic sensing using spin carrying color centers undergoing ODMR as probes, such as $\mathrm{V}_{\mathrm{Si}}$, is currently of the order of $\delta B \approx 10 \mu \mathrm{T} / \sqrt{\mathrm{Hz}}$ and can be improved in isotopically pure $\mathrm{SiC}$ to $\delta B \approx 10 \mathrm{nT} / \sqrt{\mathrm{Hz}}[51,52]$. By increasing the photoemission collection efficiency $(C)$ of the color centers and the number of emitters $(N)$, as for example in micropillars, the magnetic field sensitivity can be dramatically improved to reach magnetic sensing resolution of $\delta B \approx 10 \mathrm{nT} / \sqrt{ }(C \cdot N \cdot \mathrm{Hz})[53]$.

Here, we focus on the enhancement of the emission of the $\mathrm{V}_{\mathrm{Si}}$, $\mathrm{V}_{\mathrm{Si}} \mathrm{V}_{\mathrm{C}}$ and $\mathrm{N}_{\mathrm{C}} \mathrm{V}_{\mathrm{Si}} / 4 \mathrm{H}-\mathrm{SiC}$ platforms aiming at increasing the photon collection efficiency of many emitters to improve the resolution of quantum sensing in biomedical imaging applications due to the favorable emission in the near-infrared. We show the fabrication of micropillars with integrated $\mathrm{V}_{\mathrm{Si}}, \mathrm{V}_{\mathrm{Si}} \mathrm{V}_{\mathrm{C}}$ and $\mathrm{N}_{\mathrm{C}} \mathrm{V}_{\mathrm{Si}}$ defects to enhance spontaneous emission and collection efficiency. Compared to earlier works on applications of these materials in quantum technologies, here we focus on the formation of an ensemble of color centers at a defined position in the micropillars, rather than at a random location, for the most extensively studied emitters in $\mathrm{SiC}$ useful for spin-photon interfaces. The micropillars, although not yet optimized for an optimal collection of specific color centres, are yielding an ultra-bright emission beneficial for quantum sensing [54] applications using $\mathrm{SiC}$.

\section{Experimental Micropillar fabrication and color center generation}

In this work, micropillars were fabricated by inductively coupled plasma RIE (ICP-RIE) on commercial n-type 4H-SiC. Highly doped n-type $4 \mathrm{H}-\mathrm{SiC}$ acquired from SiCrystal was used. Using UV laser lithography and a metallic hard mask (Ti/Ni), we have realized micropillar arrays with a height of $4.5 \mu \mathrm{m}$, a diameter of $700 \mathrm{~nm}$, and a pitch of $4 \mu \mathrm{m}$. The fabrication process (Figure 1a-d) started with coating the samples with photoresist (AZ5214E) and exposing them to a UV laser $(\lambda=365 \mathrm{~nm}$, Heidelberg $\mu \mathrm{PG} 101)$. After that $5 \mathrm{~nm}$ titanium and $100 \mathrm{~nm}$ nickel were deposited as a metallic hard mask. After that, the samples were etched by ICP-RIE to produced arrays of micropillars.

The samples were then irradiated at room temperature with $300 \mathrm{keV} \mathrm{H}^{+}$at different fluences $\left(10^{16} \mathrm{~cm}^{-2}\right.$ and $\left.10^{13} \mathrm{~cm}^{-2}\right)$ to create point defects. The maximum $\mathrm{H}^{+}$concentration was simulated to be at $2 \mu \mathrm{m}$ under the sample surface. Annealing at different temperatures under neutral $\mathrm{N}_{2}$ atmosphere was used to promote the presence of different defects $\left(\mathrm{V}_{\mathrm{Si}}\right.$ without annealing, $750{ }^{\circ} \mathrm{C}$ for $30 \mathrm{~min}$ for $\mathrm{V}_{\mathrm{Si}} \mathrm{V}_{\mathrm{C}}, 900{ }^{\circ} \mathrm{C}$ for $30 \mathrm{~min}$ for $\mathrm{N}_{\mathrm{C}} \mathrm{V}_{\mathrm{Si}}$ ). The following samples were fabricated and characterized: Samples 1,2 and $3\left(\mathrm{H}^{+}\right.$fluence: $\left.10^{16} \mathrm{~cm}^{-2}\right)$ were not annealed and annealed at 750 and $900{ }^{\circ} \mathrm{C}$, respectively. Sample $4\left(\mathrm{H}^{+}\right.$fluence: $\left.10^{13} \mathrm{~cm}^{-2}\right)$ was annealed at $700{ }^{\circ} \mathrm{C}$. A summary of the sample treatments is provided in Table 1.

\section{Optical spectroscopy}

Room-temperature micro-PL was performed using the MicroRaman spectrometer LabRAM HR Evolution from HORIBA, equipped with a $785 \mathrm{~nm}$ laser. The laser is focused via a 100× 0.9 NA objective on the pillars and on the area with no pillars (gap) at the irradiation depth. The emitted photoluminescence is collected with the same objective and spectrally resolved in a spectrometer in the Czerny-Turner configuration. A Peltiercooled silicon-based charge-coupled device (CCD) is used as a line-detector in the wavelength range from 200 to $1050 \mathrm{~nm}$. A symphony II InGaAs detector cooled with liquid nitrogen to $-110{ }^{\circ} \mathrm{C}$ is used for the wavelength range from 800 to $1600 \mathrm{~nm}$.

The PL emission of the samples S1-S3 after $785 \mathrm{~nm}$ excitation (spot diameter $436 \mathrm{~nm}$ ) at room temperature is shown in Figure 2a-c, respectively; the PL emission after $671 \mathrm{~nm}$ excitation (spot diameter $250 \mathrm{~nm}$ ) at $12 \mathrm{~K}$ in shown in Figure 2d-f. The room-temperature PL shows an enhancement by a factor of 


\section{Laser Lithography}

(a)
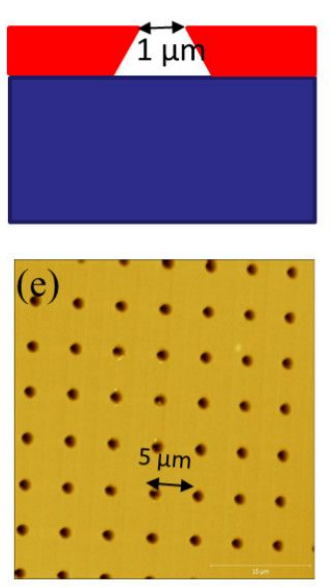

Mask deposit

(b)
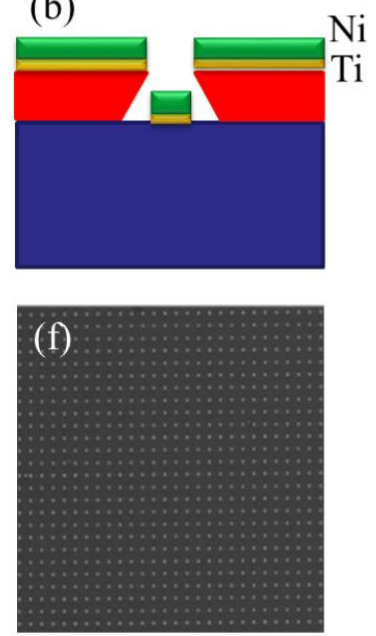

Lift off

(c)
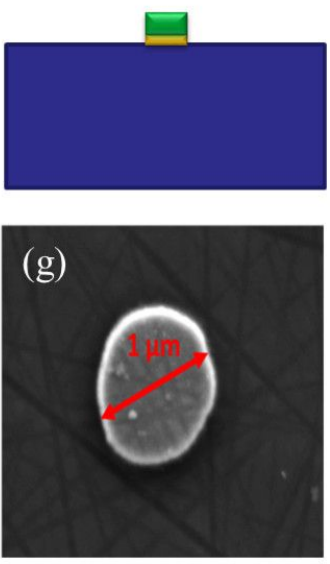

ICP etching

(d)
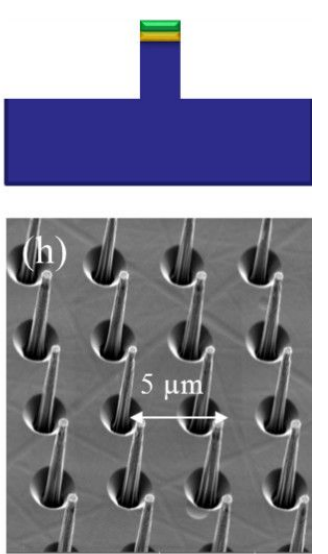

(i)
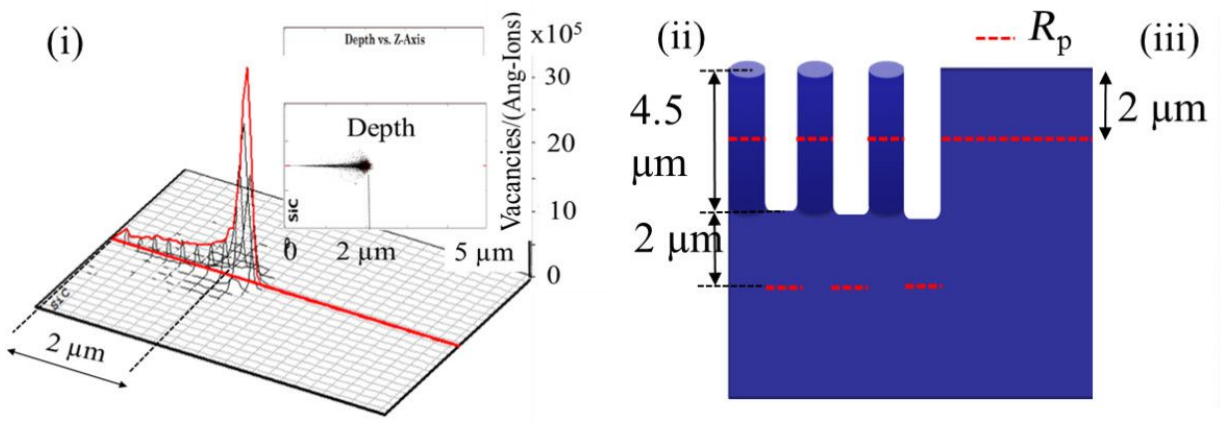

(iii)

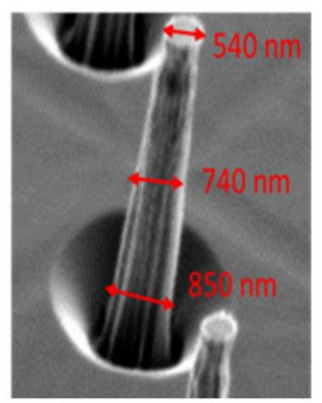

Figure 1: (a-d) Fabrication steps to obtain the 4H-SiC micropillars. (e-h) Optical microscopy and SEM images of various steps highlighted in the top row. (i) Proton irradiation SRIM simulation, with $\mathrm{H}^{+}$stopping line $\left(R_{\mathrm{p}}\right)$; (ii) schematics of the vacancy locations in the material. (iii) $\mathrm{SEM}$ image of a single pillar.

\begin{tabular}{|c|c|c|c|c|}
\hline & sample 1 (S1) & sample 2 (S2) & sample 3 (S3) & sample 4 (S4) \\
\hline fluence of $300 \mathrm{keV}$ irradiation $\left(\mathrm{H}^{+}\right.$ions $\left./ \mathrm{cm}^{2}\right)$ & $10^{16}$ & $10^{16}$ & $10^{16}$ & $10^{13}$ \\
\hline annealing temperature $\left({ }^{\circ} \mathrm{C}\right)$ & - & 750 & 900 & 700 \\
\hline color centers formation & $\mathrm{V}_{\mathrm{Si}}(\mathrm{V} 1, \mathrm{~V} 2)$ & $\mathrm{V}_{\mathrm{Si}}, \mathrm{V}_{\mathrm{Si}} \mathrm{V}_{\mathrm{C}}$ & $\mathrm{V}_{\mathrm{Si}} \mathrm{V}_{\mathrm{C}}, \mathrm{N}_{\mathrm{C}} \mathrm{V}_{\mathrm{Si}}$ & $\mathrm{V}_{\mathrm{Si}}(\mathrm{V} 1, \mathrm{~V} 2)$ \\
\hline
\end{tabular}

up to 5.5 for $\mathrm{V}_{\mathrm{Si}}$ in sample 1 and by a factor of 2.3 for $\mathrm{V}_{\mathrm{Si}} \mathrm{V}_{\mathrm{C}}$ in sample 3. Our results also confirm the conversion of $\mathrm{V}_{\mathrm{Si}}$ to $\mathrm{V}_{\mathrm{Si}} \mathrm{V}_{\mathrm{C}}$ during annealing [55] from sample 2 to sample 3. The enhancement of $\mathrm{V}_{\mathrm{Si}}$ in sample 2 appears to be lower than that in sample 1 .

The low-temperature macroscopic PL spectra show the ZPLs of $\mathrm{V}_{\mathrm{Si}}$ and $\mathrm{V}_{\mathrm{Si}} \mathrm{V}_{\mathrm{C}}$ and an important enhancement of the $\mathrm{V}_{\mathrm{Si}}$ and $\mathrm{V}_{\mathrm{Si}} \mathrm{V}_{\mathrm{C}}$ PL lines in the region where the pillars are present. It is to be noted that the gap region has also been ion-irradiated, because the irradiation was carried out without mask after the fabrication of the pillars.
For excitation at $940 \mathrm{~nm}$ the PL spectra of sample 3 shows the activation of the $\mathrm{N}_{\mathrm{C}} \mathrm{V}_{\mathrm{Si}}$ emission at low temperature [35] after annealing at a higher temperature (Figure 3). Only sample 3 at $940 \mathrm{~nm}$ excitation is shown here, as it is most exemplary for the formation of the $\mathrm{V}_{\mathrm{Si}} \mathrm{V}_{\mathrm{C}}$ and $\mathrm{N}_{\mathrm{C}} \mathrm{V}_{\mathrm{Si}}$. A detailed confocal microscopy study of $\mathrm{N}_{\mathrm{C}} \mathrm{V}_{\mathrm{Si}}$ in the pillars is given in the next section. A summary of the PL-measured color centers in each sample is reported in Table 1.

\section{Confocal microscopy}

Confocal fluorescence scanning microscopy was performed using two custom-built systems, one equipped with Si active 
(a)

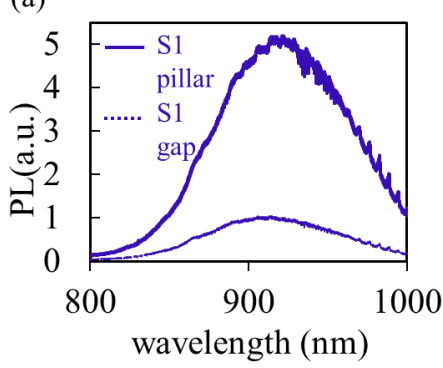

(b)
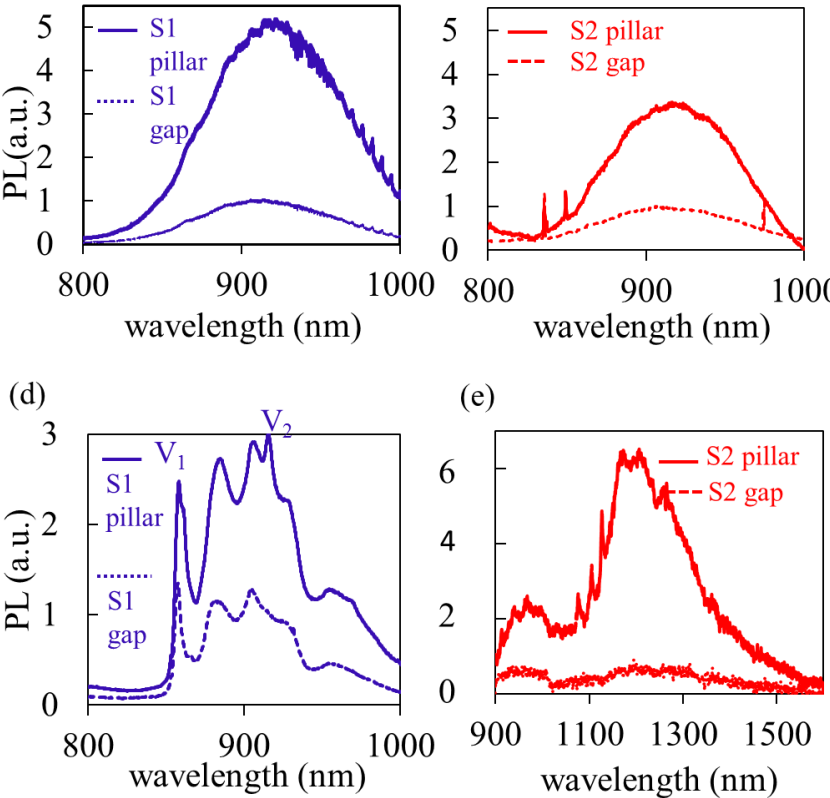

(e)

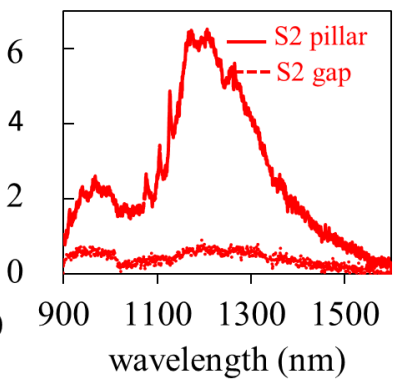

(c)

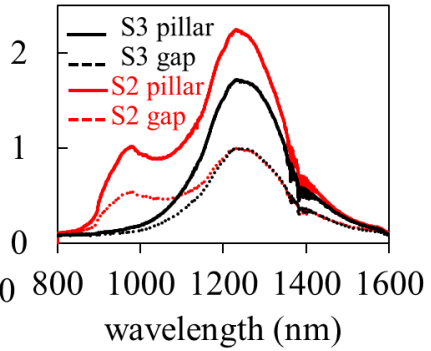

(f)

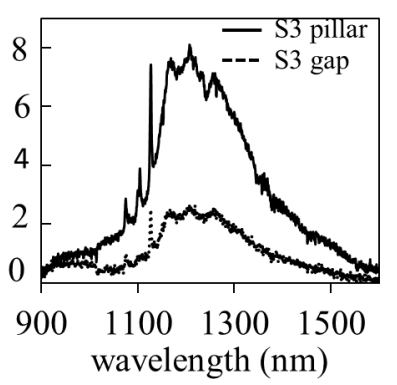

Figure 2: (a-c) Room-temperature PL spectra of the pillars and the gap area (lower dashed curves) for samples S1-S3 excited by a 785 nm CW laser. The PL curves are normalized to the maximum of the gap emission to show the enhancement. The red PL spectra in (c) refer to sample 2 and show the formation of an additional emission other than $V_{\mathrm{Si}}$ with a peak at ca. $1300 \mathrm{~nm}$. (d-f) Low-temperature (12 K) PL spectra of the pillars and gaps (lower dashed curve) of samples S1-S3 excited with $100 \mathrm{~W} / \mathrm{cm}^{2} 671 \mathrm{~nm} \mathrm{CW}$ laser. In (d) the V1 and V2 lines [30] of $\mathrm{V}_{\mathrm{Si}}$ are visible and the PL curves are normalized to the $\mathrm{V} 2$ line in the gap region. In (e) and (f), the PL1, PL2, and PL3 lines [34] of $\mathrm{V}_{\mathrm{Si}} \mathrm{V}_{\mathrm{C}}$ are clearly seen for the pillars, and the PL curves are not normalized.

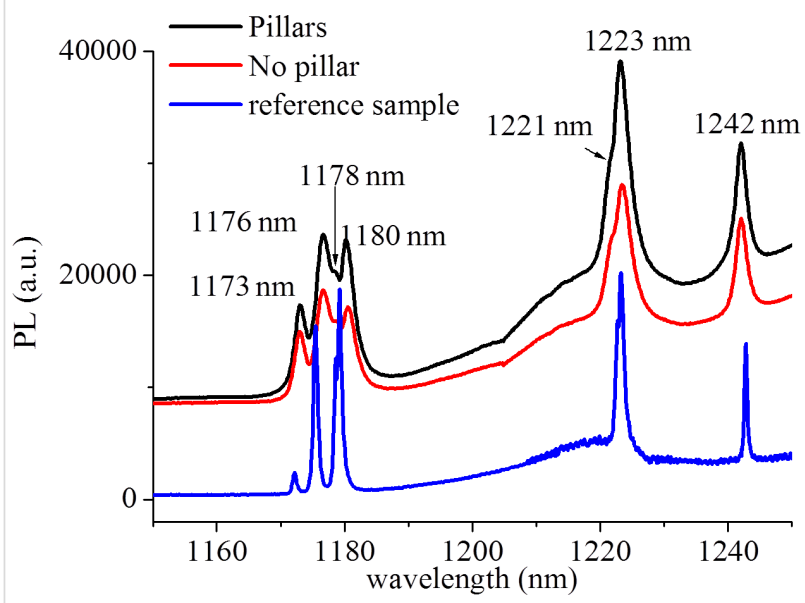

Figure 3: PL emission of sample 3 after excitation at $940 \mathrm{~nm}$ at $12 \mathrm{~K}$, showing ZPL emissions at 1221,1223 , and $1242 \mathrm{~nm}[35,38,39]$ attributed to $\mathrm{NV}$ in $4 \mathrm{H}-\mathrm{SiC}$ in the micropillars in addition to the ZPLs of the divacancy [34]. The ZPLs from $1173-1180 \mathrm{~nm}$ are due to $V_{C} V_{S i}$. The spectrum referred to as reference sample was characterized in $[38,39]$ and is given here to prove the emission is indeed due to $\mathrm{NV}$ in $4 \mathrm{H}-\mathrm{SiC}$.

quenching avalanche single-photon detectors for measuring the $\mathrm{V}_{\mathrm{Si}}$ emission and one equipped with InGaAs avalanche singlephoton detectors (ID-Quantique 230 Peltier cooled to $-90{ }^{\circ} \mathrm{C}$, quantum efficiency maximum of $25 \%$ at $1300 \mathrm{~nm}$ and set at
$10 \%$ efficiency during measurement, and dead time set at $2 \mu \mathrm{s}$ ) to measure the $\mathrm{N}_{\mathrm{C}} \mathrm{V}_{\mathrm{Si}}$ emission (Figure 4).

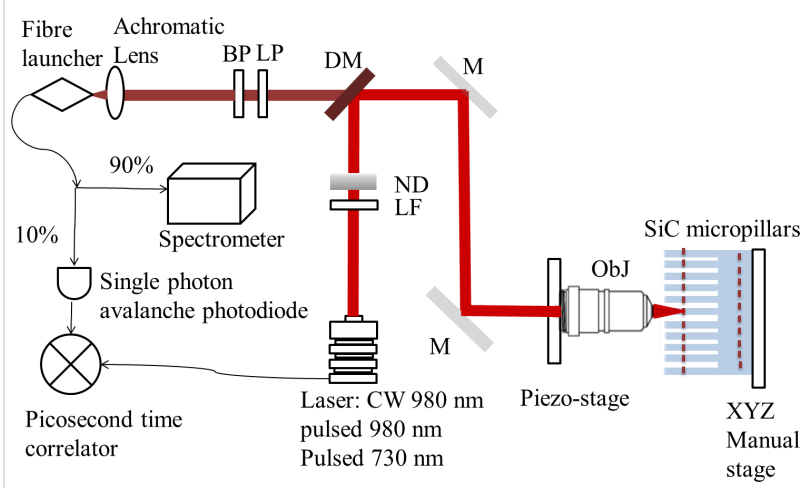

Figure 4: General schematics of the confocal systems used for imaging, spectroscopy and lifetime measurements. The schematics of the SiC micropillars sample is magnified and not to scale for illustration purposes.

In the first confocal microscopy setup a variable wavelength super continuum NKT Photonics, Fianium WhiteLase pulsed laser was used for sample illumination at $730 \mathrm{~nm}$. The laser has a pulse width of $30 \mathrm{ps}$ and a repetition rate variable from $10 \mathrm{MHz}$ to $80 \mathrm{MHz}$. The excitation wavelength to perform the 
photo counts, photo stability, and power saturation measurements was set to $730 \mathrm{~nm}$ ( $25 \mathrm{~nm}$ bandwidth) and $80 \mathrm{MHz}$. For lifetime measurements we used 40 or $10 \mathrm{MHz}$. The laser power was finely controlled using a neutral density filter wheel (ND). An Olympus dry objective (100×, 0.85 NA) LCPLN-IR with $85 \%$ transmission at $900 \mathrm{~nm}$ was used. The objectives were mounted on a PI XYZ computer-controlled stage with an XYZ closed-loop positioner with $200 \mu \mathrm{m}$ travel in each direction and a step size resolution of $1 \mathrm{~nm}$. The samples were mounted on an $\mathrm{XYZ}$ manual stage. The in-plane optical resolution was approximately $500-600 \mathrm{~nm}$ at $730 \mathrm{~nm}$ excitation. The excitation laser was reflected by a dichroic mirror (DM) single edge at $785 \mathrm{~nm}$ (Di02-R785-25x36 from Semrock, transmission $>93 \%$ between 804.3 and $1200 \mathrm{~nm}$ ) and the collected photoluminescence signal was transmitted back to the detection arm and filtered using a Thorlabs $850 \mathrm{~nm}$ longpass filter (LP, FEL0850). The fluorescence signal was collected using an achromatic aspherical converging lens of $100 \mathrm{~mm}$ focal length and sent using a fiber launcher to a multimode $1 \mathrm{~m}$ patch fiber coated from 700 to $1500 \mathrm{~nm}$, with $62.5 \mu \mathrm{m}$ core used as an aperture. The photons are then sent to a single-photon active quenching Si avalanche photodiode. The system is also equipped with a Timeharp260 correlator card from Picoquant to measure the optical lifetime of the emitters.
The second confocal microscopy setup is similar to the one described above with all optics optimized for IR emission. A CW $980 \mathrm{~nm}$ diode laser was used to excite the sample and perform confocal mapping, a DM (Semrock Di02-R1064-25x36, filters are LP Semrock BLP02-1319R at $1319 \mathrm{~nm}$ and a band-pass filter (BP) from Edmund optics at $1350 \pm 50 \mathrm{~nm}$ were used to collect the emission signal from $\mathrm{N}_{\mathrm{C}} \mathrm{V}_{\mathrm{Si}}$. PL is measured in the IR using $90 \%$ of the emission from the color centers using a Spectrometer Princeton with a PyLoN-IR camera cooled with liquid nitrogen to $-110{ }^{\circ} \mathrm{C}$. A femtosesond $80 \mathrm{MHz}$ pulsed Laser Insight $\mathrm{x} 3$ Spectra-Physics at $980 \mathrm{~nm}$ was used to measure the lifetime of the NV centers.

\section{Results and Discussion Confocal imaging}

Typical confocal images of micropillars in the different samples are shown in Figure 5 when excited at $730 \mathrm{~nm}$, with a focal spot diameter of ca. $429 \mathrm{~nm}$. The confocal microscope can perform up to $200 \times 200 \mu \mathrm{m}^{2}$ image scans, while in Figure 5 we show images of ca. $20 \times 20$ micropillars corresponding to about $100 \times 100 \mu \mathrm{m}$. The bright spots correspond to the individual pillars in the arrays. The fluorescence signal was collected through an $850 \mathrm{~nm}$ long-pass filter in order to remove any residual red emission from the $730 \mathrm{~nm}$ excitation. The ob-

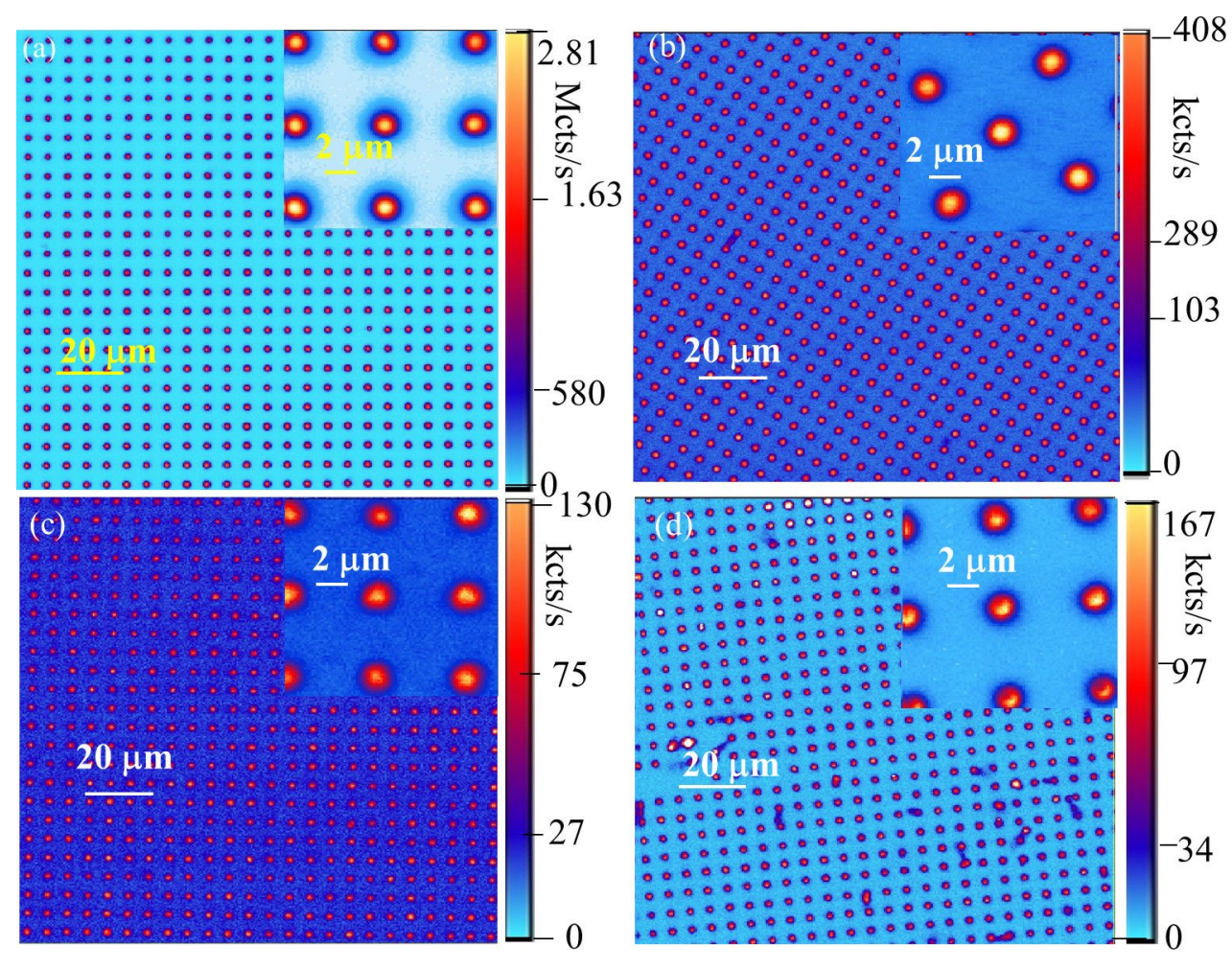

Figure 5: Confocal image and zoom image of a $10 \times 10 \mu \mathrm{m}^{2} \mathrm{~V}_{\mathrm{Si}}$ fluorescent micropillar array excited by a $730 \mathrm{~nm}$ laser. (a) Sample 1 excited by $30 \mu \mathrm{W}$ laser power. (b) Sample 2 excited by $0.7 \mathrm{~mW}$ laser power. (c) Sample 3 excited by $1.5 \mathrm{~mW}$ laser power. (d) Sample 4 excited by $4.3 \mathrm{~mW}$ laser power. An Olympus 0.85 NA infrared objective was used. 
served fluorescence signal varied depending on the annealing temperature, as only the $\mathrm{V}_{\mathrm{Si}}$ emission signal was detected, with a very bright emission well above the millions of counts per second at excitations below $100 \mu \mathrm{W}$ from sample 1 . We observed an emission signal of the $160 \mathrm{kcts} / \mathrm{s}$ in sample 4, corresponding to many emitters. Based on the results from [56,57] the ion fluence values to create single emitters are in the range from $10^{10}$ to $10^{11} \mathrm{~cm}^{-2}$. Thus, we only have an ensemble of $\mathrm{V}_{\mathrm{Si}}$ defects. A larger background was observed in samples 2 and 3, compared to samples 1 and 4 . This is probably because the annealing may induce another emission with ZPLs around $820 \mathrm{~nm}$ and a sideband in our detection region [55].

A typical confocal image of micropillars in sample 3 (optimized for the formation of the $\mathrm{N}_{\mathrm{C}} \mathrm{V}_{\mathrm{Si}}$ ) is shown in Figure $6 \mathrm{a}$ during excitation at $980 \mathrm{~nm}$. The bright spots correspond to the individual pillars in the arrays. The fluorescence was collected through a $1319 \mathrm{~nm}$ long pass filter and a $1350 \mathrm{~nm}$ band-pass filter to primarily collect $\mathrm{N}_{\mathrm{C}} \mathrm{V}_{\mathrm{Si}}$.

The $\mathrm{N}_{\mathrm{C}} \mathrm{V}_{\mathrm{Si}}$ emission in the micropillars is very bright. The confocal microscope collects only $10 \%$ of the photons, while
$90 \%$ is sent to the spectrometer (a fiber 10:90 beam splitter was used to image and measure PL at the same time), because each pillar emits around $1 \mathrm{Mcts} / \mathrm{s}$ at $100 \mu \mathrm{W}$ excitation, and the detectors are limited to less than $500000 \mathrm{cts} / \mathrm{s}$ due to the long dead time. In Figure $6 \mathrm{~b}$ the PL spectra of four pillars using confocal microscopy is compared to the emission spectra in the gap and the background arising from the deeper implanted areas.

\section{Fluorescence photostability, PL enhancement, lifetime}

Photostability measurements showed a photostable emission for all color centers. The inset of Figure $6 \mathrm{c}$ shows the photostability of the $\mathrm{N}_{\mathrm{C}} \mathrm{V}_{\mathrm{Si}}$ centers with an enhancement by a factor of four. However, the emission brightness can be different from pillar to pillar with a maximum emission enhancement by a factor of seven seen in the $1350 \mathrm{~nm}$ region. In Figure $7 \mathrm{a}$ the photostability of $\mathrm{V}_{\mathrm{Si}}$ of sample 1 and sample 4 is shown. For each investigated sample with ensemble $\mathrm{V}_{\mathrm{Si}}$ defects, an excitation laser power-dependent saturation curve of the PL was collected, as shown in Figure $7 \mathrm{~b}$ for samples 1 and 2 . The saturation curve was also studied for $\mathrm{N}_{\mathrm{C}} \mathrm{V}_{\mathrm{Si}}$ in sample 3 . The emis-
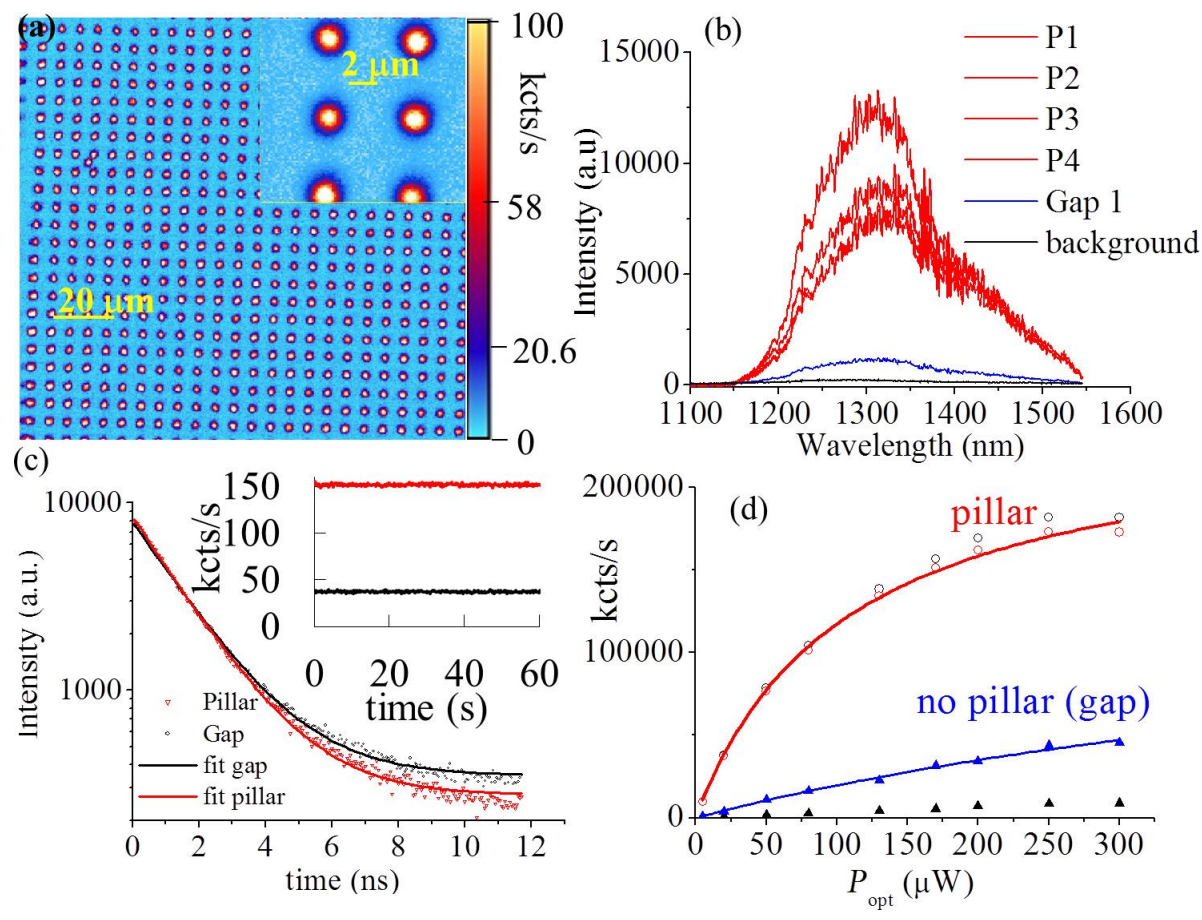

Figure 6: Confocal image and zoom image of a $10 \times 10 \mu \mathrm{m}^{2} \mathrm{~N}_{\mathrm{C}} \mathrm{V}_{\mathrm{Si}}$ fluorescent micropillars array excited by a $980 \mathrm{~nm}$ laser, recorded using InGaAs single-photon detectors. An Olympus 0.85 NA infrared objective was used. (a) Sample 3 excited with $100 \mu \mathrm{W}$ laser power, with only $10 \%$ collection emission sent to the single-photon detectors for imaging and integrated count rate, using a LP at $1319 \mathrm{~nm}$ and a BP at $1350 \pm 50 \mathrm{~nm}$. (b) PL for a few single pillars measured with $90 \%$ emission collected by a spectrometer with a InGaAs CCD camera using a LP at $1100 \mathrm{~nm}$. The PL of the pillars is compared with emission from the gap and from the background. (c) Lifetime measurement of a single pillar emission using a LP at $1319 \mathrm{~nm}$ and of the emission from the gap. Inset: Photostability of a single pillar emission using a BP at $1350 \pm 50 \mathrm{~nm}$ and an exaction power of $10.5 \mu \mathrm{W}$ compared to the gap region. An enhancement by a factor of four is measured. (d) The saturation count rate of one pillar and the gap region, showing the pillar saturation at $108 \mu \mathrm{W}$ optical power, while the gap region is saturated at $674 \mu \mathrm{W}$. The saturation curve is corrected for the background indicated by the black triangles. 

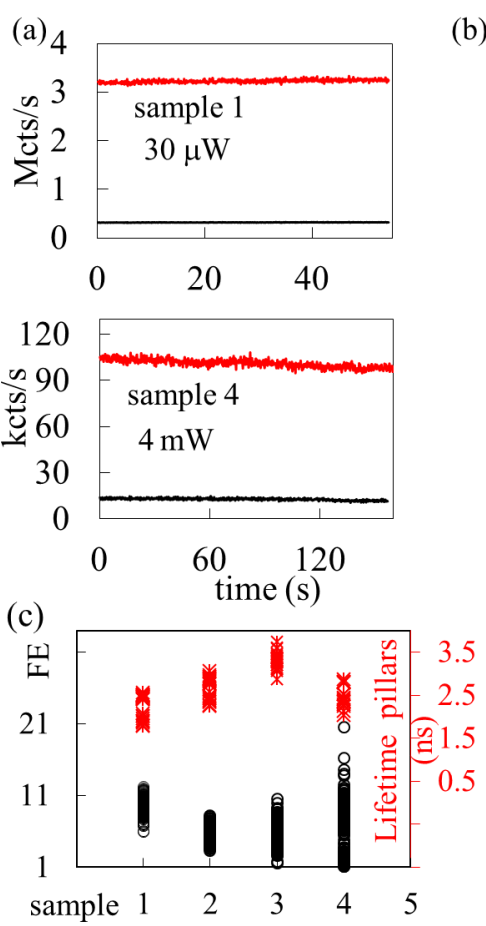

(b)

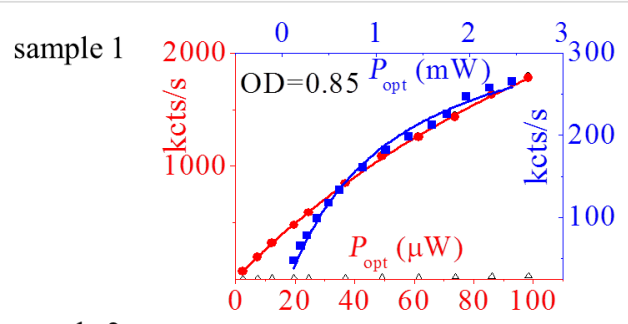

sample 2

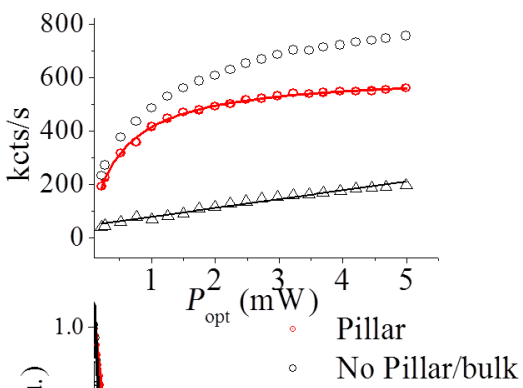

(d)

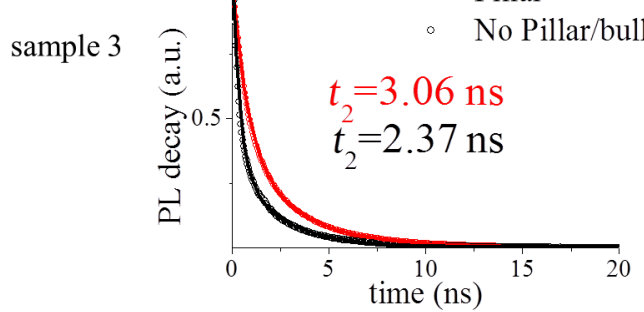

Figure 7: (a) Photostability of one micropillar and the gap region for samples 1 (top) and 4 (bottom) at excitation powers of $30 \mu \mathrm{W}$ and $4 \mathrm{~mW}$, respectively. Both samples provide a fluorescence enhancement by a factor of about ten. Counts rate are measured every 167 ms. (b) Top: Power saturation curve for one pillar in sample 1 (red) compared with the saturation count rate of the emission in the bulk (blue). The saturation curves show the enhanced emission in the pillar by a factor of 14 and a reduction of the saturation optical power by a factor of 5.6. A neutral density filter with $\mathrm{OD}=0.85$ was used to perform the measurement. Bottom: Saturation curves for one pillar in sample 2 , showing the total count rate, the background, and the signal. (c) Fluorescence enhancement (FE) of more than 100 pillars in different samples (circles) and related lifetime of the emitters in different nanopillars of the four samples. (d) Example of lifetime measurements for $V_{S i}$ in the pillar and in the gap for sample 3 , two exponentials decays were observed, the long component of the lifetime is shown. The ratio of the lifetime between the emitters in the bulk and in the pillar (for the longest pillar lifetime measured), $\mathrm{T}_{\text {bulk }} / T_{\text {pillar, }}$ is 0.77 .

sion, after background-correcting the count rate, as a function of the optical excitation power $P_{\text {opt }}$, is modeled by

$$
\phi=\frac{\phi_{\infty} P_{\mathrm{opt}}}{P_{\mathrm{opt}}+P_{\mathrm{sat}}},
$$

where $\phi$ is the collected count rate, $\phi_{\infty}$ is the count rate at saturation, and $P_{\text {sat }}$ is the excitation power at which saturation occurs. For sample 1 the power saturation measurements were performed for the emitters in pillars and for the emitters in the gap, using a neutral density filter of $\mathrm{OD}=0.85$ (attenuation of a factor of 7.1). In the pillars a saturation count rate of $\phi_{\infty}=5268 \pm 185 \mathrm{kcts} / \mathrm{s}$ at $P_{\text {sat }}=194 \pm 9 \mu \mathrm{W}$ was obtained, while in the gap, corresponding to bulk emission, the saturation occurs at the optical power of $P_{\text {sat }}=1.09 \pm 0.09 \mathrm{~mW}$, with a saturation count rate of $\phi_{\infty}=373 \pm 14 \mathrm{kcts} / \mathrm{s}$. In sample 1 we observed for one specific pillar an enhancement factor of 14 at saturation in terms of count rate and a reduction of the optical excitation power by a factor of 5.6. For $\mathrm{V}_{\mathrm{Si}}$ a count rate of $22 \mathrm{kcts} / \mathrm{s}$ of a single emitter in a nanopillar with optical pump saturation occurring at $3.5 \mathrm{~mW}$ has been shown previously [48]
This corresponds to a fluorescence enhancement (FE) by a factor of two to three compared to single emitters in non-fabricated samples. Thus, for sample 1 we estimate in the gap about ca. 41 emitters, assuming a count rate of a single emitter at saturation of about $9000 \mathrm{cts} / \mathrm{s}$. For sample 2 saturation occurs also at a lower optical power of $P_{\text {sat }}=485 \pm 11 \mu \mathrm{W}$ with a saturation count rate of $\phi_{\infty}=615 \pm 3 \mathrm{kcts} / \mathrm{s}$, compared to the gap with $P_{\text {sat }}=1.089 \pm 0.09 \mathrm{~mW}$ with a saturation count rate of $\phi_{\infty}=373 \pm 14 \mathrm{kcts} / \mathrm{s}$. In this specific pillar, there is only an enhancement by a factor of 1.7 at saturation. Finally, in a specific pillar of sample $3 P_{\text {sat }}=2.5 \pm 0.3 \mathrm{~mW}$ with a saturation count rate of $\left.\phi_{\infty}=206 \pm 15\right) \mathrm{kcts} / \mathrm{s}$. Samples 2 and 3 were not optimal for $\mathrm{V}_{\mathrm{Si}}$ enhancement due to the formation of other defects during annealing.

For sample 3 probed using $980 \mathrm{~nm}$ excitation and collecting using a $50 \mathrm{~nm} \mathrm{BP}$ at $1350 \mathrm{~nm}$, a saturation of the IR emission, attributed to $\mathrm{N}_{\mathrm{C}} \mathrm{V}_{\mathrm{Si}}$, occurs also at a lower optical power of $P_{\text {sat }}=107.5 \pm 0.1 \mu \mathrm{W}$ with a saturation count rate of $\phi_{\infty}=243 \pm 1 \mathrm{kcts} / \mathrm{s}$, compared to the gap with $P_{\text {sat }}=673.89 \pm 0.09 \mu \mathrm{W}$ with a saturation count rate of 
$\phi_{\infty}=153 \pm 1 \mathrm{kcts} / \mathrm{s}$ (Figure 6.d). It is to be noted that the single-photon detectors in the IR are saturating at less than $500 \mathrm{kcts} / \mathrm{s}$ due to exceptionally long deadtime $(2 \mu \mathrm{s})$ as such only $10 \%$ of the emitted photons were collected to have enough dynamic to capture saturation.

In Figure $7 \mathrm{c}$ the fluorescence enhancement of the $\mathrm{V}_{\mathrm{Si}}$ emission was measured for many pillars (more than 100) for each sample in the linear low-power pumping regime. Higher enhancements for sample 1 and sample 4 are observed, with an increased enhancement for the sample with the lower irradiation dose.

In Figure $6 \mathrm{c}$ the measured lifetimes of $\mathrm{N}_{\mathrm{C}} \mathrm{V}_{\mathrm{Si}}$ emission using a $\mathrm{LP}$ at $1319 \mathrm{~nm}$ were $\tau=1.557 \pm 0.006 \mathrm{~ns}$ in the pillar and $\tau=1.621 \pm 0.006 \mathrm{~ns}$ in the gap. The values were modeled using a single exponential. These short lifetimes indicate that the $\mathrm{N}_{\mathrm{C}} \mathrm{V}_{\mathrm{Si}}$ center can be ideally used as a bright SPS at room temperature.

The lifetime associated with $\mathrm{V}_{\mathrm{Si}}$ in the gap area was measured as $\tau=2.35 \pm 0.01 \mathrm{~ns}$, similar for all samples. These values are lower than the lifetimes of $6 \mathrm{~ns}$ in intrinsic $4 \mathrm{H}-\mathrm{SiC}[8,58]$ and of $5 \mathrm{~ns}$ in n-type $4 \mathrm{H}-\mathrm{SiC}$ [59]. This is attributed to material doping reducing the lifetime. The lifetime is higher for the pillars in samples 2 and 3 than for those in samples 1 and 4 . We attribute this difference to the annealing, which reduces the number of defects in the crystal. For $\mathrm{V}_{\mathrm{Si}}$ the lifetime was modeled by two exponential decay functions.

\section{Modeling of $\mathrm{V}_{\mathrm{Si}}$ emission in micropillars}

We model the emission of color centers in the pillars using the finite-element method COMSOL Multiphysics radio frequency module. A $\mathrm{V}_{\mathrm{Si}}$ color center is modeled as an oscillating point dipole located along the central axis of the SiC pillar. For calculations we used the index of refraction of the $\mathrm{SiC}$ domain, $n_{\mathrm{SiC}}=2.59$, at the assumed $\mathrm{V}_{\mathrm{Si}}$ emission wavelength of $900 \mathrm{~nm}$ (the center is $917 \mathrm{~nm}$ ). Considering the SEM images of the fabricated SiC pillars, the length of the SiC pillars was set to $4.3 \mu \mathrm{m}$. The top radius of the conical SiC pillars was set to $270 \mathrm{~nm}$ and the bottom radius to $425 \mathrm{~nm}$. The $\mathrm{V}_{\mathrm{Si}}$ dipole is assumed to be a linear excitation dipole along the defect axis, i.e., $8^{\circ}$ off the $c$-axis, which the micropillars are aligned to. We studied the spontaneous emission of the $\mathrm{V}_{\mathrm{Si}}$ dipole at different depths along the full length of the pillar. To have a better understanding of the calculated results, we also studied the spontaneous emission of the $\mathrm{V}_{\mathrm{Si}}$ dipole in cylindrical SiC pillars of varying radii from 160 to $600 \mathrm{~nm}$. Based on these simulations, we calculated the Purcell enhancement, the collection efficiency (CE) enhancement, and the fluorescence enhancement relative to $\mathrm{V}_{\mathrm{Si}}$ emission in bulk SiC. The Purcell enhancement is obtained in terms of the total power radiated by the dipole in the $\mathrm{SiC}$ pillar to that radiated in bulk $\mathrm{SiC}$, after considering the quantum efficiency of the emitting dipole. To obtain the collection efficiency, we measure the power collected on a circular surface at the domain top the diameter of which is chosen such that it acts as a collection lens with a numerical aperture of 0.9 (corresponding to the aperture of the collection objective of the confocal microscope). CE enhancement is then obtained as the ratio between the radiated power collected at the top surface and the radiated power collected on the same surface for dipole emission in bulk SiC. To have a comparison with the experimentally measured PL enhancement, the calculated FE is defined by the equation [60]:

$$
\mathrm{FE}=\frac{\eta_{\text {pillar }}}{\eta_{\text {bulk }}} \frac{\gamma_{\text {pillar }}}{\gamma_{\text {bulk }}} \frac{\mathrm{QE}_{\text {pillar }}}{\mathrm{QE}_{\text {bulk }}},
$$

where the color center bulk quantum efficiency, $\mathrm{QE}_{\text {bulk }}$, and the $\mathrm{SiC}$ pillar quantum efficiency, $\mathrm{QE}_{\text {pillar }}$, are assumed to be the same. Here, $\eta_{\text {pillar }} / \eta_{\text {bulk }}$ is the ratio between the collection efficiency in the $\mathrm{SiC}$ pillar and that in the bulk (CE enhancement) and $\gamma_{\text {pillar }} / \gamma_{\text {bulk }}$ is the ratio between the corresponding excitation/emission rates (Purcell enhancement). The relative excitation rates should be the same as relative emission rates for $\mathrm{QE}$ of 1 . For $\mathrm{QE}=1$, the relative emission rate is calculated as the total power radiated by the dipole emitter in the $\mathrm{SiC}$ pillar relative to that in bulk $\mathrm{SiC}$ [61]. The total emission rate is equivalent to the reciprocal of the total lifetimes,

$$
\mathrm{FE}=\frac{\gamma_{\text {pillar }}}{\gamma_{\text {bulk }}} \frac{\tau_{\text {bulk }}}{\tau_{\text {pillar }}}
$$

This ratio is almost constant due to the low $\mathrm{QE}$ of $\mathrm{V}_{\mathrm{Si}}$ in $\mathrm{SiC}$, as observed in Figure $8 b$. The $\mathrm{QE}$ of $\mathrm{V}_{\mathrm{Si}}$ is assumed to be 0.3 from previous measurements of decay associated with intersystem crossing, which were based on the decay rates from the excited state to the metastable state and to the ground state of a single emitter [8]. Other non-radiative decays due to phonon sideband and thermal dephasing are neglected here.

From the collection efficiency calculations, we found the collection efficiency to be substantially enhanced for dipole emission in the SiC pillar. For a dipole oriented $8^{\circ}$ off the $c$-axis, the $\eta_{\text {bulk }}$ value is found to be very low, ca. 0.0038 . However, in a $\mathrm{SiC}$ pillar of $350 \mathrm{~nm}$ radius $\eta_{\text {pillar }}$ varies in the range from 0.1 to 0.3 along the length of the pillar. This is more than an order of magnitude enhancement of the collection efficiency, with a possible maximum collection efficiency of $30 \%$.

In the FE calculations, we saw successive periodic peaks in the FE enhancement factor along the length of the pillar, with a 

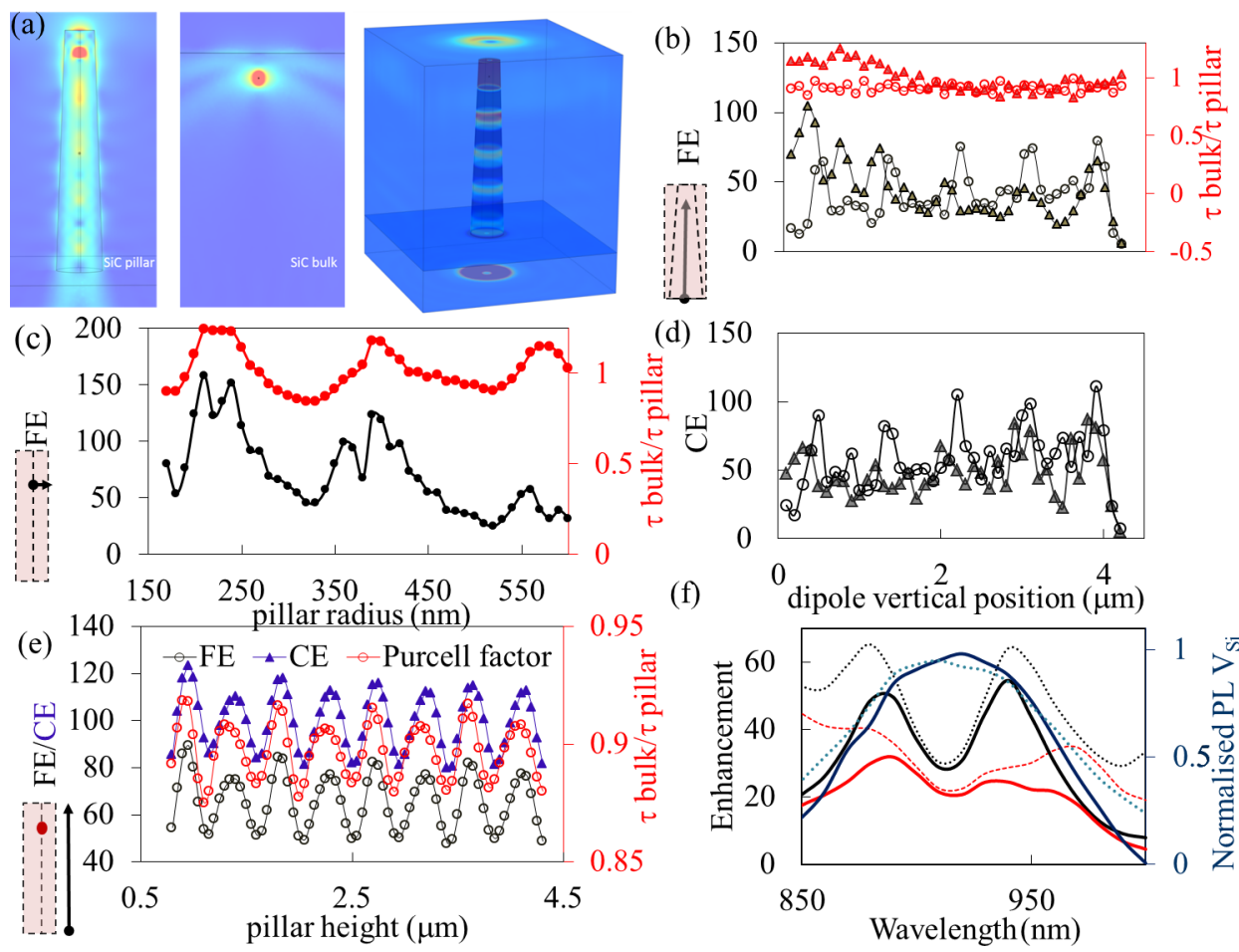

\begin{abstract}
Figure 8: Finite-element method simulation for a pillar of $4.3 \mu \mathrm{m}$ height and a dipole orientation $8^{\circ}$ off the $c$-axis. Two geometries of the pillars are considered, cylindrical (circles) and conical (triangles). (a) Radiation pattern: intensity and power outflow from a conical pillar with emitters at $3.9 \mu \mathrm{m}$ from the bottom of a pillar, compared to an emitter $400 \mathrm{~nm}$ below the bulk surface. (b) FE and $\mathrm{T}_{\text {bulk }} / \mathrm{T}_{\text {pillar }}$ as functions of the vertical position of the dipole for a cylindrical pillar of radius $350 \mathrm{~nm}$ (circles) and for the conical pillar (triangles). (c) $\mathrm{FE}$ and $\mathrm{T}_{\text {bulk }} / \mathrm{T}_{\text {pillar }}$ as functions of the radius of a cylindrical SiC pillar for a dipole located at $3.9 \mu \mathrm{m}$ from the bottom. (d) Simulated collection efficiency (CE) enhancement relative to bulk as a function of the vertical position of the dipole in a cylindrical pillar of radius $350 \mathrm{~nm}$ (circles) and for the conical pillar (triangles). (e) FE, CE, and Purcell factor as functions of the pillar height of the conical pillar with a fixed emitter at $450 \mathrm{~nm}$ from the surface. (f) FE (red lines) and CE (black lines) enhancement as functions of the wavelength for the conical pillar with an emitter located at $2.3 \mu \mathrm{m}$ from the bottom (experimental case), showing the effect of the broad emission of $\mathrm{V}_{\mathrm{Si}}$ on $\mathrm{FE}$ and $\mathrm{CE}$. The FE reduction across the spectra is ca. $24 \%$ compared to a narrow emission. Dashed lines represent the calculated enhancements, and the solid lines represent the enhancement modulated by the emission spectra of $V_{\mathrm{Si}}$, which is also shown as a dashed blue line in the bulk and solid blue line in the pillar.
\end{abstract}

spacing between the peaks of $400-450 \mathrm{~nm}$, which is about half of the dipole emission wavelength (Figure $8 \mathrm{~b}$, circles). The first peak appears at ca. $400 \mathrm{~nm}$ from the top surface (ca. $3.9 \mu \mathrm{m}$ along the pillar height). The successive nodes of the radiation pattern of the dipole emission can be seen in Figure 8a. When varying the $\mathrm{SiC}$ pillar radius, we obtained the best performance for a radius of ca. $210 \mathrm{~nm}$ (Figure 8c). This corresponds to a pillar diameter of ca. $420 \mathrm{~nm}$, about half of the dipole emission wavelength. For the optimal radius the FE enhancement factor is ca. 160 , corresponding to $\tau_{\text {bulk }} / \tau_{\text {pillar }}=1.24$. A small variation of these results is observed for the conical shape (Figure $8 \mathrm{~b}$ ). The cylindrical model yields information about the optimal radius for fabrication. We also varied the pillar height and observed successive modes separated by ca. $450 \mathrm{~nm}$, about half of the dipole emission wavelength. The optimum pillar height is $0.9 \mu \mathrm{m}$ (Figure 8e).

Under our experimental conditions (conical shape and emitters at ca. $2.3 \mu \mathrm{m}$ from the bottom), we predict $\mathrm{FE}=29$ at $900 \mathrm{~nm}$, which is reduced to 20 because of the broad emission of the center and average values of $\mathrm{CE}=31$ and $\tau_{\text {bulk }} / \tau_{\text {pillar }}=0.92$. The experimental values vary from pillar to pillar with $\mathrm{FE}=3-20$ and $\tau_{\text {bulk }} / \tau_{\text {pillar }}=0.77-0.92$. The discrepancy between the experimental results and the simulation results is attributed to the broad emission of $\mathrm{V}_{\mathrm{Si}}$ of about $100 \mathrm{~nm}$, which significantly reduces the average enhancement as shown in Figure 8f. Additionally, samples 2 and 3 are not optimal for enhancement because of the annealing and the formation of other color centers that can quench the emission. Further, the location of the emitter and the size of the pillar (radius and height) also influence fluorescence enhancement and lifetime. Our results, therefore, show overall a good match between the calculated and experimental values. They are slightly different from [50], where the best position for the emitters, to increase guiding of the nanopillars, is close to the bottom. Here, the SiC pillar height was about $800 \mathrm{~nm}$. Also, peaks in the collection efficiency can be observed at about $400 \mathrm{~nm}$ and more from the top pillar surface. 


\section{Conclusion}

We have fabricated micropillars with a deterministic placement of near-infrared color centers in $\mathrm{SiC}$ using hydrogen irradiation and annealing at different temperatures. We have optimized the enhancement of color centers relevant for quantum sensing applications, such as silicon monovacancies and divacancies, and nitrogen vacancies. Due to the high fluence during implantation, we did not observe single emitters. We achieved a spontaneous emission enhancement by a factor of up to 20 for the silicon monovacancies achieving several Mcts/s in a single pillar from the ensemble of emitters. Based on our results we foresee further optimization and studies of the micropillar design for increased resolution and sensitivity in magnetometry using these emitters [51-53,62]. An optimized design based on finite-element method analysis is also proposed for the enhancement of the $\mathrm{V}_{\mathrm{Si}}$ defect emission. The optimized design is a pillar with a radius of ca. $210 \mathrm{~nm}$ radius and a height of $0.9 \mu \mathrm{m}$ in which the emitters are localized ca. $450 \mathrm{~nm}$ from the top. This design could improve the $\mathrm{V}_{\mathrm{Si}}$ and $\mathrm{V}_{\mathrm{Si}} \mathrm{V}_{\mathrm{C}}$ SPSs collection efficiencies $[4,5,8]$ for spin-photon interfaces and quantum network applications [1]. Finally, we have enhanced by a factor of up to 7 the emission of $\mathrm{N}_{\mathrm{C}} \mathrm{V}_{\mathrm{Si}}$ in $\mathrm{SiC}$, achieving more than $2 \mathrm{Mcts} / \mathrm{s}$ photostable emission at $1350 \pm 50 \mathrm{~nm}$ in a single pillar at room temperature. Due to the remarkably high brightness of the $\mathrm{N}_{\mathrm{C}} \mathrm{V}_{\mathrm{Si}}$ in $\mathrm{SiC}$ and the measured lifetime in the range of ca. $1.6 \mathrm{~ns}$, we expect this defect to be ideal for single-photon generation. In addition, the ZFS of this defect can be optically detected. For both future experiments, FE in micropillars could be beneficial. The development demonstrated here also paves the way to achieve more sensitive quantum magnetic sensing devices, in particular for deep tissue imaging in biological analyses due to the favorable emission of $\mathrm{N}_{\mathrm{C}} \mathrm{V}_{\mathrm{Si}}$. Deep imaging of biological tissues is a significant challenge as light is scattered by the tissues, distorting the focus of optical microscopes. Imaging at optical super-resolution may be achieved by using novel devices based on the engineered defects in the $\mathrm{SiC}$ micropillars. Further optimization of the photonic structure, from quality and quantity of color centers, over unit-specific surface area as well as unit volume, to the size, shape and relative positioning of the micropillars, will be needed for specific applications.

\section{Acknowledgements}

We thank the staff of NanoLyon platform for the support using the facilities. In particular N. Terrier for the UV photolithography, R. Mazurczyk for the ICP etching and S. Brottet for SEM imaging. We thank Mr. D. Stavrevski for the technical support with the confocal microscopes at the ARC Centre of Excellence for Nanoscale Biophotonics, School of Applied Science, RMIT University. We thank Prof B. Gibson for the access to the laboratories at the ARC Centre of Excellence for
Nanoscale Biophotonics. We thank RMIT University Micro Nano Research facility for the use of the Horiba Raman system. S.-I.S. acknowledges JSPS KAKENHI Grant Numbers 17KK0137 and JP18H01483. A.F.A. acknowledges the Ministry of Education in Saudi Arabia for his Ph. D. scholarship. The authors do not have any conflict of interests to declare.

\section{Author Contributions}

S.C. designed and performed the experiments, designed the simulations, and wrote the draft paper. A.S.Al A., J.M.B. and GG designed and fabricated the samples and performed micro PL at low temperature. F.A.I. performed the COMSOL modeling and provided insight into the models' results. S.H. and H.v.B. performed the low-temperature micro PL experiment in the IR. A.F.A. performed micro PL at room temperature. S.-I.S. aided on the optimization of the confocal setup, in the identification of the IR color centers and discussed and commented on the confocal results. S.C. and A.B. wrote the manuscript. All authors discussed the manuscript.

\section{ORCID ${ }^{\circledR}$ iDs}

Stefania Castelletto - https://orcid.org/0000-0002-8675-2291 Abdul Salam Al Atem - https://orcid.org/0000-0002-4421-3628 Shin-ichiro Sato - https://orcid.org/0000-0001-9359-9400 Alberto Boretti - https://orcid.org/0000-0002-3374-0238 Jean Marie Bluet - https://orcid.org/0000-0002-1672-6725

\section{References}

1. Atatüre, M.; Englund, D.; Vamivakas, N.; Lee, S.-Y.; Wrachtrup, J. Nat. Rev. Mater. 2018, 3, 38-51. doi:10.1038/s41578-018-0008-9

2. Weber, J. R.; Koehl, W. F.; Varley, J. B.; Janotti, A.; Buckley, B. B.; Van de Walle, C. G.; Awschalom, D. D. Proc. Natl. Acad. Sci. U. S. A. 2010, 107, 8513-8518. doi:10.1073/pnas.1003052107

3. Awschalom, D. D.; Hanson, R.; Wrachtrup, J.; Zhou, B. B. Nat. Photonics 2018, 12, 516-527. doi:10.1038/s41566-018-0232-2

4. Widmann, M.; Lee, S.-Y.; Rendler, T.; Son, N. T.; Fedder, H.; Paik, S.; Yang, L.-P.; Zhao, N.; Yang, S.; Booker, I.; Denisenko, A.; Jamali, M.; Momenzadeh, S. A.; Gerhardt, I.; Ohshima, T.; Gali, A.; Janzén, E.; Wrachtrup, J. Nat. Mater. 2015, 14, 164-168. doi:10.1038/nmat4145

5. Christle, D. J.; Falk, A. L.; Andrich, P.; Klimov, P. V.; Hassan, J. U.; Son, N. T.; Janzén, E.; Ohshima, T.; Awschalom, D. D. Nat. Mater. 2015, 14, 160-163. doi:10.1038/nmat4144

6. Christle, D. J.; Klimov, P. V.; de las Casas, C. F.; Szász, K.; Ivády, V.; Jokubavicius, V.; UI Hassan, J.; Syväjärvi, M.; Koehl, W. F.; Ohshima, T.; Son, N. T.; Janzén, E.; Gali, Á.; Awschalom, D. D. Phys. Rev. X 2017, 7, 021046. doi:10.1103/physrevx.7.021046

7. Castelletto, S.; Johnson, B. C.; Ivády, V.; Stavrias, N.; Umeda, T.; Gali, A.; Ohshima, T. Nat. Mater. 2014, 13, 151-156. doi:10.1038/nmat3806

8. Fuchs, F.; Stender, B.; Trupke, M.; Simin, D.; Pflaum, J.; Dyakonov, V.; Astakhov, G. V. Nat. Commun. 2015, 6, 7578. doi:10.1038/ncomms 8578 
9. Lohrmann, A.; Johnson, B. C.; McCallum, J. C.; Castelletto, S. Rep. Prog. Phys. 2017, 80, 034502. doi:10.1088/1361-6633/aa5171

10. Lienhard, B.; Schröder, T.; Mouradian, S.; Dolde, F.; Tran, T. T.; Aharonovich, I.; Englund, D. Optica 2016, 3, 768-774. doi:10.1364/optica.3.000768

11. Kraus, H.; Soltamov, V. A.; Riedel, D.; Väth, S.; Fuchs, F.; Sperlich, A.; Baranov, P. G.; Dyakonov, V.; Astakhov, G. V. Nat. Phys. 2014, 10, 157-162. doi:10.1038/nphys2826

12. Wolfowicz, G.; Whiteley, S. J.; Awschalom, D. D. Proc. Natl. Acad. Sci. U. S. A. 2018, 115, 7879-7883. doi:10.1073/pnas.1806998115

13. de las Casas, C. F.; Christle, D. J.; UI Hassan, J.; Ohshima, T.; Son, N. T.; Awschalom, D. D. Appl. Phys. Lett. 2017, 111, 262403. doi: $10.1063 / 1.5004174$

14. Lohrmann, A.; Iwamoto, N.; Bodrog, Z.; Castelletto, S.; Ohshima, T.; Karle, T. J.; Gali, A.; Prawer, S.; McCallum, J. C.; Johnson, B. C. Nat. Commun. 2015, 6, 7783. doi:10.1038/ncomms8783

15. Widmann, M.; Niethammer, M.; Makino, T.; Rendler, T.; Lasse, S.; Ohshima, T.; UI Hassan, J.; Tien Son, N.; Lee, S.-Y.; Wrachtrup, J. Appl. Phys. Lett. 2018, 112, 231103. doi:10.1063/1.5032291

16. Sato, S.-i.; Honda, T.; Makino, T.; Hijikata, Y.; Lee, S.-Y.; Ohshima, T. ACS Photonics 2018, 5, 3159-3165. doi:10.1021/acsphotonics.8b00375

17. Yan, F.-F.; Wang, J.-F.; Li, Q.; Cheng, Z.-D.; Cui, J.-M.; Liu, W.-Z.; Xu, J.-S.; Li, C.-F.; Guo, G.-C. Phys. Rev. Appl. 2018, 10, 044042. doi:10.1103/physrevapplied.10.044042

18. Bracher, D. O.; Hu, E. L. Nano Lett. 2015, 15, 6202-6207. doi:10.1021/acs.nanolett.5b02542

19. Song, B.-S.; Yamada, S.; Asano, T.; Noda, S. Opt. Express 2011, 19 , 11084-11089. doi:10.1364/oe.19.011084

20. Kira, M.; Jahnke, F.; Koch, S. W. Phys. Rev. Lett. 1999, 82, 3544-3547. doi:10.1103/physrevlett.82.3544

21. Zavoisky, E. J. J. Phys. (Moscow) 1945, 9, 211-245.

22. Sild, O.; Haller, K., Eds. Zero-Phonon Lines; Springer Berlin: Berlin, Germany, 1988. doi:10.1007/978-3-642-73638-4

23. Debye, P. Ann. Phys. (Berlin, Ger.) 1913, 348, 49-92. doi:10.1002/andp.19133480105

24. Waller, I. Z. Phys. 1923, 17, 398-408. doi:10.1007/bf01328696

25. Atherton, N. M. Principles of electron spin resonance; Ellis Horwood: Chichester, United Kingdom, 1993

26. Delaney, P.; Greer, J. C.; Larsson, J. A. Nano Lett. 2010, 10, 610-614. doi:10.1021/nl903646p

27. Nagy, R.; Niethammer, M.; Widmann, M.; Chen, Y.-C.; Udvarhelyi, P.; Bonato, C.; Hassan, J. U.; Karhu, R.; Ivanov, I. G.; Son, N. T.; Maze, J. R.; Ohshima, T.; Soykal, Ö. O.; Gali, Á.; Lee, S.-Y.; Kaiser, F.; Wrachtrup, J. Nat. Commun. 2019, 10, 1954. doi:10.1038/s41467-019-09873-9

28. Sörman, E.; Son, N. T.; Chen, W. M.; Kordina, O.; Hallin, C.; Janzén, E. Phys. Rev. B 2000, 61, 2613-2620. doi:10.1103/physrevb.61.2613

29. Simin, D.; Soltamov, V. A.; Poshakinskiy, A. V.; Anisimov, A. N.; Babunts, R. A.; Tolmachev, D. O.; Mokhov, E. N.; Trupke, M.; Tarasenko, S. A.; Sperlich, A.; Baranov, P. G.; Dyakonov, V.; Astakhov, G. V. Phys. Rev. X 2016, 6, 031014. doi:10.1103/physrevx.6.031014

30. Ivády, V.; Davidsson, J.; Son, N. T.; Ohshima, T.; Abrikosov, I. A.; Gali, A. Phys. Rev. B 2017, 96, 161114. doi:10.1103/physrevb.96.161114
31. Nagy, R.; Widmann, M.; Niethammer, M.; Dasari, D. B. R.; Gerhardt, I.; Soykal, Ö. O.; Radulaski, M.; Ohshima, T.; Vučković, J.; Son, N. T.; Ivanov, I. G.; Economou, S. E.; Bonato, C.; Lee, S.-Y.; Wrachtrup, J. Phys. Rev. Appl. 2018, 9, 034022. doi:10.1103/physrevapplied.9.034022

32. Banks, H. B.; Soykal, Ö. O.; Myers-Ward, R. L.; Gaskill, D. K.; Reinecke, T. L.; Carter, S. G. Phys. Rev. Appl. 2019, 11, 024013. doi:10.1103/physrevapplied.11.024013

33. Economou, S. E.; Dev, P. Nanotechnology 2016, 27, 504001. doi:10.1088/0957-4484/27/50/504001

34. Koehl, W. F.; Buckley, B. B.; Heremans, F. J.; Calusine, G.; Awschalom, D. D. Nature 2011, 479, 84-87. doi:10.1038/nature10562

35. von Bardeleben, H. J.; Cantin, J. L.; Rauls, E.; Gerstmann, U. Phys. Rev. B 2015, 92, 064104. doi:10.1103/physrevb.92.064104

36. von Bardeleben, H. J.; Cantin, J. L.; Csóré, A.; Gali, A.; Rauls, E.; Gerstmann, U. Phys. Rev. B 2016, 94, 121202. doi:10.1103/physrevb.94.121202

37. Zargaleh, S. A.; Hameau, S.; Eble, B.; Margaillan, F.; von Bardeleben, H. J.; Cantin, J. L.; Gao, W. Phys. Rev. B 2018, 98 , 165203. doi:10.1103/physrevb.98.165203

38. Zargaleh, S. A.; Eble, B.; Hameau, S.; Cantin, J.-L.; Legrand, L.; Bernard, M.; Margaillan, F.; Lauret, J.-S.; Roch, J.-F.; von Bardeleben, H. J.; Rauls, E.; Gerstmann, U.; Treussart, F. Phys. Rev. B 2016, 94, 060102. doi:10.1103/physrevb.94.060102

39. Zargaleh, S. A.; von Bardeleben, H. J.; Cantin, J. L.; Gerstmann, U.; Hameau, S.; Eblé, B.; Gao, W. Phys. Rev. B 2018, 98, 214113. doi:10.1103/physrevb.98.214113

40. Sato, S.-i.; Narahara, T.; Abe, Y.; Hijikata, Y.; Umeda, T.; Ohshima, T. J. Appl. Phys. 2019, 126, 083105. doi:10.1063/1.5099327

41. Reithmaier, J. P.; Sęk, G.; Löffler, A.; Hofmann, C.; Kuhn, S.; Reitzenstein, S.; Keldysh, L. V.; Kulakovskii, V. D.; Reinecke, T. L.; Forchel, A. Nature 2004, 432, 197-200. doi:10.1038/nature02969

42. Ding, X.; He, Y.; Duan, Z.-C.; Gregersen, N.; Chen, M.-C.; Unsleber, S.; Maier, S.; Schneider, C.; Kamp, M.; Höfling, S.; Lu, C.-Y.; Pan, J.-W. Phys. Rev. Lett. 2016, 116, 020401. doi:10.1103/physrevlett.116.020401

43. Reitzenstein, S.; Forchel, A. J. Phys. D: Appl. Phys. 2010, 43, 033001. doi:10.1088/0022-3727/43/3/033001

44. Shin, C.; Jin, H.-H.; Kim, W.-J.; Park, J.-Y. J. Am. Ceram. Soc. 2012, 95, 2944-2950. doi:10.1111/j.1551-2916.2012.05346.x

45. Jang, Y.-S.; Zollfrank, C.; Jank, M.; Greil, P. J. Am. Ceram. Soc. 2010, 93, 3929-3934. doi:10.1111/j.1551-2916.2010.03978.x

46. Calusine, G.; Politi, A.; Awschalom, D. D. Appl. Phys. Lett. 2014, 105, 011123. doi:10.1063/1.4890083

47. Lukin, D.; Dory, C.; Radulaski, M.; Sun, S.; Mishra, S. D.; Guidry, M.; Vercruysse, D.; Vučković, J. 4H-SiC-on-Insulator Platform for Quantum Photonics. In Conference on Lasers and Electro-Optics, OSA Technical Digest (Optical Society of America, 2019), San Jose, CA, U.S.A., May 5-10, 2019; OSA Publishing, 2019. doi:10.1364/cleo_si.2019.sm2f.6

48. Magyar, A. P.; Bracher, D.; Lee, J. C.; Aharonovich, I.; Hu, E. L. Appl. Phys. Lett. 2014, 104, 051109. doi:10.1063/1.4863932

49. Lohrmann, A.; Karle, T. J.; Sewani, V. K.; Laucht, A.; Bosi, M.; Negri, M.; Castelletto, S.; Prawer, S.; McCallum, J. C.; Johnson, B. C. ACS Photonics 2017, 4, 462-468. doi:10.1021/acsphotonics.6b00913

50. Radulaski, M.; Widmann, M.; Niethammer, M.; Zhang, J. L.; Lee, S.-Y.; Rendler, T.; Lagoudakis, K. G.; Son, N. T.; Janzén, E.; Ohshima, T.; Wrachtrup, J.; Vučković, J. Nano Lett. 2017, 17, 1782-1786. doi:10.1021/acs.nanolett.6b05102 
51. Kraus, H.; Soltamov, V. A.; Fuchs, F.; Simin, D.; Sperlich, A.; Baranov, P. G.; Astakhov, G. V.; Dyakonov, V. Sci. Rep. 2014, 4, No. 5303. doi:10.1038/srep05303

52. Simin, D.; Fuchs, F.; Kraus, H.; Sperlich, A.; Baranov, P. G.; Astakhov, G. V.; Dyakonov, V. Phys. Rev. Appl. 2015, 4, 014009. doi:10.1103/physrevapplied.4.014009

53. Ohshima, T.; Satoh, T.; Kraus, H.; Astakhov, G. V.; Dyakonov, V.; Baranov, P. G. J. Phys. D: Appl. Phys. 2018, 51, 333002. doi:10.1088/1361-6463/aad0ec

54. Degen, C. L.; Reinhard, F.; Cappellaro, P. Rev. Mod. Phys. 2017, 89, 035002. doi:10.1103/revmodphys.89.035002

55. Rühl, M.; Ott, C.; Götzinger, S.; Krieger, M.; Weber, H. B. Appl. Phys. Lett. 2018, 113, 122102. doi:10.1063/1.5045859

56. Kraus, H.; Simin, D.; Kasper, C.; Suda, Y.; Kawabata, S.; Kada, W.; Honda, T.; Hijikata, Y.; Ohshima, T.; Dyakonov, V.; Astakhov, G. V. Nano Lett. 2017, 17, 2865-2870. doi:10.1021/acs.nanolett.6b05395

57. Wang, J.; Zhou, Y.; Zhang, X.; Liu, F.; Li, Y.; Li, K.; Liu, Z.; Wang, G.; Gao, W. Phys. Rev. Appl. 2017, 7, 064021. doi:10.1103/physrevapplied.7.064021

58. Hain, T. C.; Fuchs, F.; Soltamov, V. A.; Baranov, P. G.; Astakhov, G. V.; Hertel, T.; Dyakonov, V. J. Appl. Phys. 2014, 115, 133508. doi:10.1063/1.4870456

59. Castelletto, S.; Almutairi, A. F. M.; Thalassinos, G.; Lohrmann, A.; Buividas, R.; Lau, D. W. M.; Reineck, P.; Juodkazis, S.; Ohshima, T.; Gibson, B. C.; Johnson, B. C. Opt. Lett. 2017, 42, 1297-1300. doi:10.1364/ol.42.001297

60. Akselrod, G. M.; Argyropoulos, C.; Hoang, T. B.; Ciracì, C.; Fang, C.; Huang, J.; Smith, D. R.; Mikkelsen, M. H. Nat. Photonics 2014, 8, 835-840. doi:10.1038/nphoton.2014.228

61. Xu, Y.; Vučković, J. S.; Lee, R. K.; Painter, O. J.; Scherer, A.; Yariv, A. J. Opt. Soc. Am. B 1999, 16, 465-474. doi:10.1364/josab.16.000465

62. Cochrane, C. J.; Blacksberg, J.; Anders, M. A.; Lenahan, P. M. Sci. Rep. 2016, 6, 37077. doi:10.1038/srep37077

\section{License and Terms}

This is an Open Access article under the terms of the Creative Commons Attribution License (http://creativecommons.org/licenses/by/4.0). Please note that the reuse, redistribution and reproduction in particular requires that the authors and source are credited.

The license is subject to the Beilstein Journal of Nanotechnology terms and conditions:

(https://www.beilstein-journals.org/bjnano)

The definitive version of this article is the electronic one which can be found at: $\underline{\text { doi:10.3762/bjnano.10.229 }}$ 